\title{
Response of TLD and RPL personal dosimeters in a national inter-comparison test program
}

\author{
N. Navab Moghadam, S.M. Hosseini Pooya ${ }^{2,3^{*}}$, H. Afarideh', \\ M.R. Kardan',3
}

\author{
${ }^{1}$ Faculty of Energy Engineering and Physics, Amirkabir University of Technology, Tehran, Iran \\ ${ }^{2}$ Nuclear Safety and Radiological Protection Research Department, Nuclear Science and Technology Research \\ Institute, Tehran, Iran \\ 3Iran Nuclear Regulatory Authority, Tehran, Iran
}

\section{Technical note}

\section{*Corresponding author:}

Mr. Seyed Mahdi Hosseini Pooya, Fax: +982188221125

E-mail: mhosseini@aeoi.org.ir

Revised: Feb. 2015

Accepted: April 2015

Int. J. Radiat. Res., January 2016; 14(1): $73-76$

DOI: 10.18869 /acadpub.ijrr.14.1.73

\begin{abstract}
Background: Different kinds and models of personal dosimeters are used in individual monitoring by workers. Performance testing as part of approval procedures is carried out to demonstrate that the essential performance specifications are routinely maintained. There are four service providers in Iran which use different luminescence techniques (i. e. TLD and RPL) with various kinds of dosimeter materials/reader instruments in personal dosimetry services. Materials and Methods: A national performance approval tests program was performed for the dosimeters of the service providers in energy range of soft, $660 \mathrm{keV}$ and $1.25 \mathrm{MeV}$, at the doses values around the recoding, investigation and annual dose limits, and different angle of incidents (e. g. 0, 20, 40 and 60 degree). Results: The results of this testing satisfies the overall accuracy criteria with $95 \%$ confidence levels specified by the ICRP, except that of RPL technique in low energy which overestimates the dose out of the acceptable accuracy band defined as the ICRP trumpet curves. Conclusion: The inter-comparison has proved that the personal dose equivalent quantity, $H_{p}(10)$, defined by the ICRU and recommended by the IAEA are becoming widely accepted and implemented in most participated laboratories.
\end{abstract}

Keywords: TLD, RPL, dosimetry, inter-comparison, individual, performance, tests.

\section{INTRODUCTION}

There are different kinds of passive dosimetry methods that service providers may use them in individual monitoring. Among the methods, luminescence techniques inclusive of thermally stimulated luminescence (TLD), radio-photoluminescence (RPL) and optically stimulated luminescence (OSL) are the most general accurate methods in this regard (1).

There are many factors such as energy and angular dependency which may increase the uncertainty of measurements. So laboratories in different countries plan the inter-comparison approval test programs demonstrating the full fillment of uncertainties of measurements (2-5). Since some laboratories may have not benefited systematic calibration procedures as described by ISO-4037 (6) or used inappropriate dosimeters, the related dosimetry response are obtained out of the standard criteria. Thus, the main advantage of an inter-comparison program is that the service provider may be notified for a required improvement on their dosimetry systems. As well it shows the reliability of any laboratory measuring the personal dose operational quantity.

Based upon the ICRP criteria for personal dosimetry, the overall accuracy in measurements should be satisfied at different 
dose limits. These evaluations are being done via a performance test program as a part of approval procedures by a competent authority to demonstrate that the essential performance specifications are routinely maintained (7).

The National Radiation Protection Department (NRPD) of Iran Nuclear Regulatory Authority (INRA) is the regulatory body supervising all the service providers in Iran.

There are four private service providers which use the luminescence techniques in their personal dosimetry services covering approximately five thousand workers in various radiation practices in Iran.

In this research, the procedures and results of the first national performance approval tests program performed by the regulatory body are discussed.

\section{MATERIALS AND METHODS}

The types of dosimeters which have been used in the program are shown in figure 1. These are inclusive of TLD-100 (LiF: Mg, Ti, USA) and GR-200 (LiF: Mg, Cu, P, China) dosimeters which are placed in HARSHAW, RADOS, PTW and a home-made badges. Moreover one of the service providers uses RPL dosimeters of model UIF-01 (Glass material, Russia) in their services. The configuration of dosimeter-badges which are used by the service providers are presented in table 1.

The dosimeters were irradiated by a generator of $120 \mathrm{kVp}$, a ${ }^{137} \mathrm{Cs}$ source $(660 \mathrm{keV})$, and a ${ }^{60} \mathrm{C} 0$ source $(1.25 \mathrm{MeV})$ in the Secondary Standard Dosimetry Laboratory (SSDL) of Iran. All the requirements of ISO-4037 standards were considered in irradiations (6). All the dosimeters were exposed at different angles of incident by value of $0,20,40$ and 60 degree (figure 2). 36 dosimeters of each type have been used in the program.

The ICRP trumpet curves have been calculated with the assumption that the recoding level to be $0.1 \mathrm{mSv}$ by value for a bimonthly/ quarterly periodic dosimetry time. The operational quantity of personal dose equivalent, $H_{\mathrm{p}}(10)$ was used in the program.
The trumpet curves of ICRP are calculated as:

$$
\begin{gathered}
R_{L L}=_{\frac{1}{1.5}\left(1-\frac{2 H_{0}}{H_{0}+H_{1}}\right) \quad \begin{array}{c}
\text { for }_{1}<H_{0} \\
\text { for } H_{1} \geq H_{0}
\end{array}} \\
R_{U L}=1.5\left(1+\frac{H_{0}}{2 H_{0}+H_{1}}\right)
\end{gathered}
$$

where, $R_{L L}$ and $R_{L U}$ are the low and high level curves respectively, $H_{0}$ is the recoding level value, and $H_{1}$ is the true doses (7). In this work, based upon the recoding, investigation and annual dose limits, the true dose were selected arounds the limits as $\simeq 0.7,2.4$ and $25 \mathrm{mSv}$.

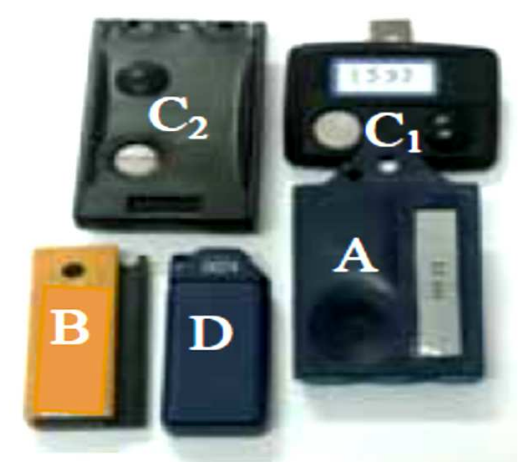

Figure 1. Type of dosimeters/badges which have been used in the intercomparison program (Labels are defined in table 1 which is $a, b, c, d)$.

Table 1. The dosimeter-badges which are used by the service providers.

\begin{tabular}{|c|c|c|}
\hline $\begin{array}{c}\text { Label of Service } \\
\text { Provider }\end{array}$ & Type of dosimeter & $\begin{array}{c}\text { Type of } \\
\text { badge }\end{array}$ \\
\hline A & LiF: $\mathrm{Mg}, \mathrm{Ti}$ & Home-made \\
\hline B & LiF: Mg, Cu, P & PTW \\
\hline \multirow{2}{*}{ C } & (1) LiF, Mg, Ti & RADOS \\
\cline { 2 - 3 } & (2) LiF: Mg, Cu, P & HARSHAW \\
\hline D & RPL & UIF-01 \\
\hline
\end{tabular}

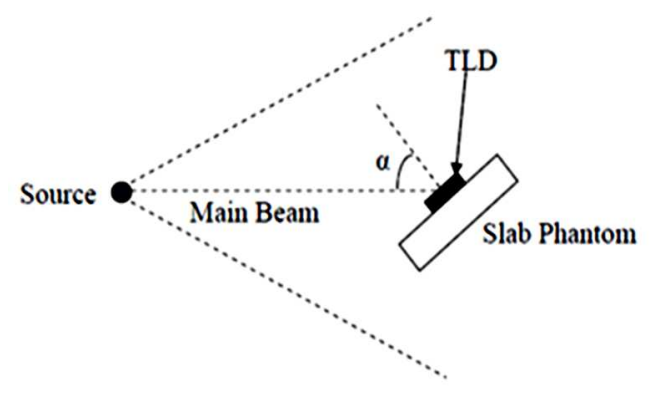

Figure 2. Schematic diagram of exposure configuration for angular dependency, $\alpha=0,20,40$ and $60^{\circ}$. 
A response curve should be constructed for each type of radiation by calculating and plotting the average angular response for each energy $\varepsilon$ (7):

$$
\bar{R}_{\varepsilon}=0.25\left(R_{\varepsilon, 0}+R_{\varepsilon, 20}+R_{\varepsilon, 40}+R_{\varepsilon, 60}\right)
$$

where $R_{\varepsilon, \alpha}$ is the response at energy $\varepsilon$ and incident angle $\alpha$, and

$$
R_{\varepsilon, \alpha}=\frac{\left(H_{\varepsilon, \alpha}\right)_{m}}{\left(H_{\varepsilon, \alpha}\right)_{t}}
$$

where $\left(H_{\varepsilon, \alpha}\right)_{m}$ is the measured dose and $\left(H_{\varepsilon, \alpha}\right)_{t}$ is the conventional true value.

\section{RESULTS AND DISCUSSION}

The $R_{E}$ values of various dosimeters (table 1 ) derived from equations 2 and 3 at different angles of incidence are presented in table 2 . The total uncertainty of each measurement inclusive of calibration errors, repeatability measurements, and linearity of response was measured less than $10 \%$ by value.

The obtained results show a good angular dependency for the GR-200 TLDs in PTW badges (B), and TLD-100 in home-made badges (A). Furthermore the RPL dosimeters (D) overestimate the true dose values in soft energy region.

Figure 3 shows the trumpet curves derived from equation 1 along with the plotted values $\overline{\boldsymbol{R}}_{\boldsymbol{\varepsilon}}$ (as the points) for the various dosimeters in the national performance test program. The obtained values for TLD-Based individual dosimeters place inside of the trumpet curves. However, the TLD dosimeters which contain LiF: $\mathrm{Mg}, \mathrm{Cu}, \mathrm{P}$ dosimeters underestimate the dose in energy range, in contrast with $\mathrm{LiF}: \mathrm{Mg}$, $\mathrm{Ti}$ dosimeters which overestimate it regardless of the type/shape of badges. Nevertheless, both of the related values of dosimeters are placed inside of the trumpet curves. The results are compatible with the energy response of bare dosimeters which have been already reported by other investigators $(8,9)$.

Moreover, the response of RPL dosimeter overestimates the true dose at energy range out of the trumpet curve, however there is no problem at higher energies. The results are compatible with the energy response of the unfiltered dosimeter presented by David and Shih in 2011 which are shown in figure 4 (10). As it can be seen in the figure, the relative energy response of unfiltered RPL dosimeter is higher than that of both filtered RPL and $\mathrm{LiF}: \mathrm{Mg}, \mathrm{Cu}$, $\mathrm{P}(\mathrm{TLD}-100 \mathrm{H})$ at low energy region. This is due to photoelectric interaction of low energy with high effective atomic number elements (e. g. Ag) within dosimeter which increases the dose response of the RPL dosimeter. So the dosimeter is more appropriate in high energy gamma radiation fields.

In summary, the results show that most measurements fulfill the established requirements, but some difficulties are still found for the low-energy photons in RPL dosimeters.

Although there is some correlation within services that were using the same TLD materials/badges, it could not be concluded that a specific type of system was always better than another. The laboratory "a" obtained excellent results within all doses at all energies/angles of incidences.

Table 2. $R_{E}$ values of various model of dosimeters at different angles of incident (the uncertainty of each measurement was measured less than $10 \%$ by value).

\begin{tabular}{|c|c|c|c|c|c|c|c|c|c|c|c|c|}
\hline \multirow{2}{*}{ Dosimeter } & \multicolumn{4}{|c|}{ Soft } & \multicolumn{4}{|c|}{ Y-radiation of ${ }^{\mathbf{1 3 7}}$ Cs } & \multicolumn{4}{c|}{ Y-radiation of ${ }^{\mathbf{6 0}}$ Co } \\
\cline { 2 - 14 } & $0^{\circ}$ & $20^{\circ}$ & $40^{\circ}$ & $60^{\circ}$ & $0^{\circ}$ & $20^{\circ}$ & $40^{\circ}$ & $60^{\circ}$ & $0^{\circ}$ & $20^{\circ}$ & $40^{\circ}$ & $60^{\circ}$ \\
\hline A & 1.44 & 1.25 & 0.97 & 1.19 & 1.04 & 1.11 & 1.13 & 1.22 & 1.07 & 0.98 & 0.97 & 1.10 \\
\hline B & 0.60 & 0.60 & 0.60 & 0.60 & 1.28 & 1.00 & 0.87 & 1.12 & 1.06 & 1.27 & 1.10 & 1.15 \\
\hline C1 & 1.14 & 1.97 & 1.54 & 1.53 & 1.90 & 1.70 & 1.22 & 1.18 & 0.97 & 1.14 & 1.13 & 1.12 \\
\hline C2 & 0.71 & 0.81 & 0.79 & 0.72 & 0.97 & 0.91 & 0.92 & 1.80 & 1.00 & 0.91 & 1.00 & 1.05 \\
\hline D & 3.13 & 2.42 & 2.58 & 2.00 & 0.93 & 0.97 & 1.13 & 1.05 & 1.03 & 1.04 & 1.05 & 1.02 \\
\hline
\end{tabular}



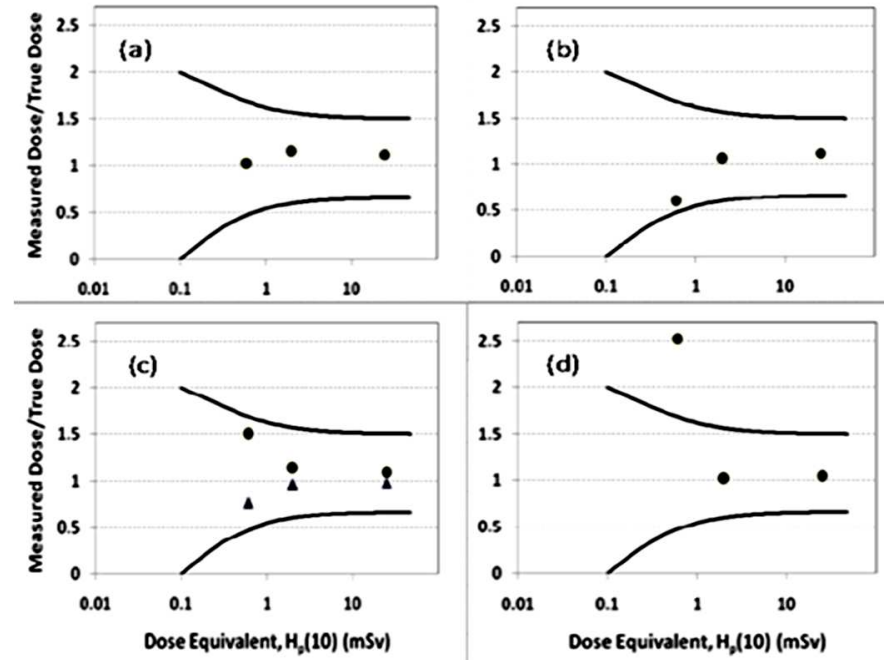

Figure 3. $\bar{R}_{\boldsymbol{\varepsilon}}$ values for the various dosimeters of the service providers in the national performance test program, (a) LiF: Mg, Ti in Home-made badge, (b) LiF:Mg, $\mathrm{Cu}, \mathrm{P}$ in PTW badge, (c) · LiF: $\mathrm{Mg}$, $\mathrm{Ti}$ in RADOS badge, LiF:Mg, Cu, $\mathrm{P}$ in Harshaw badge (d) RPL in UIF-01 badge.

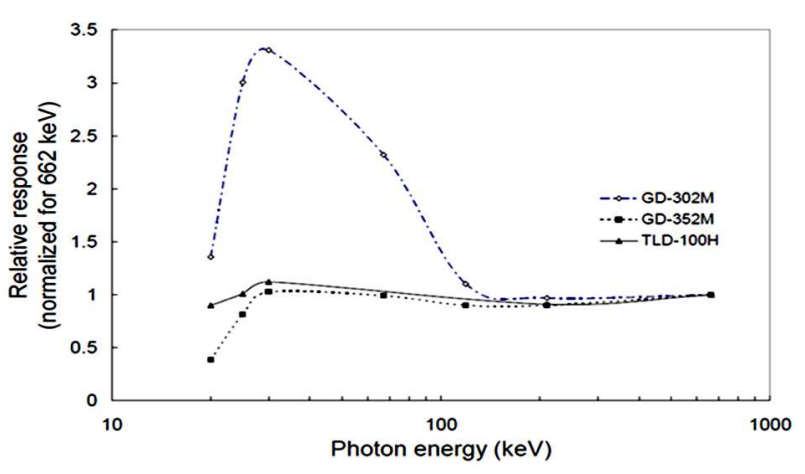

Figure 4. Energy dependency of unfiltered GD-302M RPL, filtered GD-352M RPL and LiF: Mg, Cu, P (TLD-100H Harshaw) TLD dosimeters $^{(10)}$.

\section{CONCLUSION}

A national performance test program was carried out for the personal dosimeters of four private service providers which are using different luminescence techniques in Iran. According to the obtained results, it can be concluded that the overall accuracy criteria are satisfied with $95 \%$ confidence levels specified by the ICRP. However, it has also identified one RPL service which should revise and improve its measurements procedure for low energy's.

Conflicts of interest: none to declare.

\section{REFERENCES}

1. Botter-Jensen L (1997) Luminescence Techniques: Instrumentation and methods. Radiat Meas, 27: 749-768.
2. Murakami h, Minami k, Griffith RV (1994) Results of the IAEA/RCA Personal Dosimeter Intercomparison in the Asian and Pacific Region. Radiat Prot Dosim, 54: 19-23.

3. Villanueva I, hernández A, Amor I, Muñoz MJ (2001) Spanish intercomparisons for individual monitoring. Radiat Prot Dosim, 96: 201-203.

4. Gregori BN, Papadópulos SB, Saraví M, Kunst JJ (2007) Argentine intercomparison programme for personal dosimetry. Radiat Prot Dosim, 125(1-4): 98-100.

5. Carinoua E, Donadilleb L, Ginjaumec M, Jankowskid J, Rimplere A, Sans Mercef M, Vanhavereg F, Denoziereh M, Dauresh J, Bordyh JM, Itieb C, Covensi P (2008) Intercomparison on measurements of the quantity personal dose equivalent $H_{p}(0.07)$, by extremity ring dosimeters in medical fields. Radiat Meas, 43 (2-6): 565-570.

6. ISO 4037-3 (199) $X$ and gamma reference radiation for calibrating dosimeters and doserate meters and for determining their response as a function of photon energy. Part 3: Calibration of area and personal dosimeters and the measurement of their response as a function of energy and angle of incidence. International Organization for Standardization, Geneva, Switzerland.

7. IAEA- Safety Standards Series (1999) RS-G-1.3, Assessment of occupational exposure due to external sources of radiation.

8. Muhogora WE, Ngoya WN, Lema US, Mwalongo D (2002) Energy response of LiF: $\mathrm{Mg}$, Ti dosimeter to ISO 4037 and typical diagnostic beams in Tanzania. J Radio Prot, 22: 175-184.

9. Duggan L, Hood C, Warren-Forward H, Haque M, Kron $T$ (2004) Variations in dose response with energy of LiF: $\mathrm{Mg}, \mathrm{Cu}, \mathrm{P}$ thermoluminescence dosimeters: mplications for clinical dosimetry. Phys Medic Biol, 49: 3831-3845.

10. Huang DYC and Hsu SM (2011) Radio-Photoluminescence Glass Dosimeter (RPLGD), Advances in Cancer Therapy, Prof. Hala Gali-Muhtasib (Ed.), ISBN: 978-953-307-703-1. 